\title{
Degree Diameter Problem on Oxide Networks
}

\section{Akhtar MS*}

Centre for Advanced Studies in Pure and Applied Mathematics, Bahauddin Zakariya University, Multan, Pakistan

\begin{abstract}
The degree diameter problem is the problem of finding the largest graph (in terms of number of vertices) subject to the constraints on the degree and the diameter of the graph. Beyond the degree constraint there is no restriction on the number of edges (apart from keeping the graph simple) so the resulting graph may be thought of as being embedded in the complete graph. In a generalization of this problem, the graph is considered to be embedded in some connected host graph. This article considers embedding the graph in the oxide network and provides some exact values and some upper and lower bounds for the optimal graphs.
\end{abstract}

Keywords: Oxide network; Degree; Diameter; Silicon vertex; Oxygen vertex; Closed ball; Tetrahedron; Triangle

\section{Introduction}

All graphs considered in this paper are simple, finite and undirected. The degree of a vertex in the graph $G$ is the number of edges incident with that vertex in $G$. The maximum and minimum degree of the graph $\mathrm{G}$ is denoted by $\Delta(\mathrm{G})$ and $\delta(\mathrm{G})$, respectively. The distance between two vertices $x$ and $y$ of $G$ is the length of the shortest path between them. The distance between a vertex $\mathrm{x}$ and the set $A$ is defined as $d(x, A)=\min _{a \in A} d(x, a)$. The diameter of the graph $\mathrm{G}$ is denoted by $\mathrm{D}$ and is defined as the maximum pairwise distance between the vertices of the graph G. For a given graph $\mathrm{G}$ and positive integers $\Delta$ and $D, N_{G}(\Delta, D)$ denote the order of a largest subgraph of $G$ with given maximum degree $\Delta$ and given diameter $\mathrm{D}$. For definitions and notations not defined here we refer to the text [1-4]. The degree/ diameter problem (DDP) is a quest to find the largest graphs, in terms of the number of vertices, given constraints on the maximum degree of the graph and its diameter [5-10]. For a thorough survey of the state of the problem $[11,12]$. Because the maximum degree is the only restriction on the distribution of edges, there is considerable freedom in placing edges so as to avoid violating the diameter constraint. The degree diameter problem of honeycomb and triangular networks have been studied [5,6]. The largest sub graph $\mathrm{N}_{\mathrm{G}}(\Delta, \mathrm{D})$ have been determined with multidimensional rectangular Mesh and the multidimensional hexagonal grid as host graphs $[7,10]$.

Silicates are obtained by fusing metal oxides or metal carbonates with sand. Essentially all the silicates contain $\mathrm{Sio}_{4}$ tetrahedra. In chemistry, the corner vertices of sio $_{4}$ tetrahedron represent oxygen ions and the center vertex represents the silicon ion [2]. In graph theory, the tetrahedra unit $\mathrm{sio}_{4}$ is the complete graph $\mathrm{K}_{4}$. We call the corner vertices as oxygen nodes and the center vertex as silicon node.

The graph of silicate network can be constructed in different ways [3]. The silicate network SL(1) is a cyclic silicate with six $\mathrm{Sio}_{4}$ tetrahedra units. The silicate network SL(2) is obtained by adding six units of SL(1) such that each outer SL(1) shares two consecutive tetrahedra of inner SL(1). Inductively, silicate network SL(n) of dimension $n$ is obtained from SL(n-1) by adding a layer of SL(1) around the boundary of SL(n-1). The number of nodes in SL(n) is $15 n^{2+} 3 n$ and the number of edges of $\mathrm{SL}(\mathrm{n})$ is $36 \mathrm{n}^{2}$. In Figure 1a, a silicate network of dimension two is shown [2].

\section{The Graph of Oxide Network}

When all the silicon nodes are deleted from a silicate network, we obtain a new network which we shall call as an oxide network. An $\mathrm{n}$-dimensional oxide network is denoted by $\mathrm{OX}(\mathrm{n})$ having number of vertices $9 n^{2}+3 n$ and number of edges $18 n^{2}$ [4]. An oxide network of dimension 2 is shown in Figure $1 b$ [4]. The distance of a vertex $x \in V$ (G) from a triangle $T$ is $\min _{y \in V_{(T)}} d_{G}(x, y)$ and will be denoted by $d_{G}(x, T)$, where the vertex $y$ is the closest vertex of $T$ from $x$. The properties of oxide networks have been studied in various aspect [2-4]. In this paper, we have studied the degree diameter problem of oxide networks.

In the following sections, we consider the cases when $\Delta=4$ and $\Delta=1,2,3$ separately.

\section{Values for $\Delta=4$}

Let $\mathrm{X}$ denote the infinite oxide network in the Euclidean plane and we consider $\mathrm{X}$ as a host graph. Note that $\Delta(\mathrm{X})=4$.

\section{Proposition 1.1}

For even $\mathrm{D} \geq 4$, Let the induced sub graph of $\mathrm{X}$ denoted by $\mathrm{O}_{\mathrm{D}}$

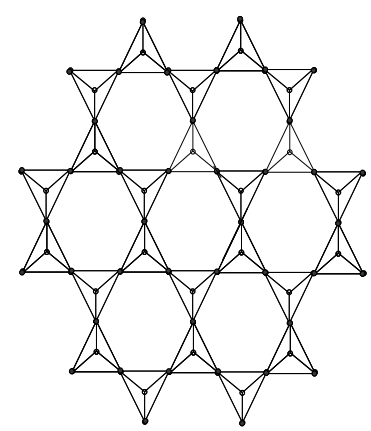

(a) $\operatorname{SL}(2)$

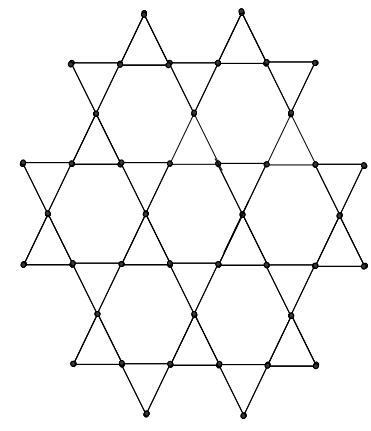

(b) $\mathrm{OX}(2)$
Figure 1: Graph

${ }^{*}$ Corresponding author: Akhtar MS, Centre for Advanced Studies in Pure and Applied Mathematics, Bahauddin Zakariya University, Multan, Pakistan, Tel: +92 61 9210097; E-mail: shahzadmeo9@gmail.com

Received July 20, 2017; Accepted January 03, 2018; Published January 10 2018

Citation: Akhtar MS (2018) Degree Diameter Problem on Oxide Networks. J Appl Computat Math 7: 377. doi: 10.4172/2168-9679.1000377

Copyright: (c) 2018 Akhtar MS. This is an open-access article distributed under the terms of the Creative Commons Attribution License, which permits unrestricted use, distribution, and reproduction in any medium, provided the original author and source are credited. 
is a closed ball of radius $\frac{D}{2}$ with center as a common vertex $m$ of two triangles with vertex set $\left\{x \in V(\mathrm{X}): \mathrm{d}_{\mathrm{x}}(\mathrm{x}, \mathrm{m}) \leq \frac{D}{2}\right\}$ then

$$
\left|V\left(\mathrm{O}_{\mathrm{D}}\right)\right|=\left\{\begin{array}{l}
9 k^{2}+5 k, \quad \text { for } D=4 k . \\
9 k^{2}+13 k+5, \text { for } D=4 k+2
\end{array}\right.
$$

where $\mathrm{k} \in \mathrm{N}$.

\section{Proof}

For even $\mathrm{D} \geq 4, \mathrm{O}_{\mathrm{D}}$ is the closed ball of radius $\frac{D}{2}$ with center as a common vertex of two triangles and $\Delta=4$. Now we draw horizontal lines on the vertices of $\mathrm{O}_{\mathrm{D}}$ and count the vertices on each horizontal line one by one then adding them for top to bottom we have.

For $\mathrm{D}=4 \mathrm{k}, \mathrm{k} \in \mathbb{N}$, then

$\left|\mathrm{V} \quad\left(\mathrm{O}_{\mathrm{D}}\right)\right|=2 \mathrm{k}+(\mathrm{k}+1)+\ldots+(4 \mathrm{k}-3)+(2 \mathrm{k}-1)+(4 \mathrm{k}-1)+2 \mathrm{k}+(4 \mathrm{k}$ $+1)+2 \mathrm{k}+(4 \mathrm{k}-1)+(2 \mathrm{k}-1)+\ldots+(2 \mathrm{k}+3)+(\mathrm{k}+1)+2 \mathrm{k}$

$=9 \mathrm{k}^{2+} 5 \mathrm{k}$

For $\mathrm{D}=4 \mathrm{k}+2, \mathrm{k} \in \mathbb{N}$, then

$\left|\mathrm{V}\left(\mathrm{O}_{\mathrm{D}}\right)\right|=(\mathrm{k}+1)+(2 \mathrm{k}+3)+\ldots+(4 \mathrm{k}-1)+2 \mathrm{k}+(4 \mathrm{k}+1)+(2 \mathrm{k}+1)+$

$(4 \mathrm{k}+3)+(2 \mathrm{k}+1)+(4 \mathrm{k}+1)+2 \mathrm{k}+(4 \mathrm{k}-1)+\ldots+(2 \mathrm{k}+3)+(\mathrm{k}+1)$

$=9 \mathrm{k}^{2+} 13 \mathrm{k}+5$

In the Figures $2 a$ and $2 b$ the graphs $O_{D}$ for $D=4$ and $D=6$ are depicted where the central vertex $n$ of $\mathrm{O}_{\mathrm{D}}$ is depicted by $\otimes$.

\section{Proposition 1.2}

For odd $\mathrm{D}>4$, Let the induced sub graph of $\mathrm{X}$ denoted by

$\mathrm{O}_{\mathrm{D}}$ is a closed ball of radius $\frac{D-1}{2}$ with center as a triangle with vertex set $\left\{x \in V(\mathrm{X}): \mathrm{d}_{\mathrm{x}}(\mathrm{x}, \mathrm{m}) \leq \frac{D-1}{2}\right\}$, where $\mathrm{n}$ is the vertex of the central triangle which is closest to $\mathrm{x}$ then

$$
\left|V\left(\mathrm{O}_{\mathrm{D}}\right)\right|= \begin{cases}9 k^{2}+9 k+3 & \text { for } D=4 k+1 . \\ 9 k^{2}+18 k+9, & \text { for } D=4 k+3 .\end{cases}
$$

where $\mathrm{k} \in \mathrm{N}$

\section{Proof}

For odd $\mathrm{D}>4, \mathrm{O}_{\mathrm{D}}$ is the closed ball of radius $\frac{D-1}{2}$ with center as a triangle and $\Delta=4$. Now we draw horizontal lines on the vertices of $\mathrm{O}_{\mathrm{D}}$
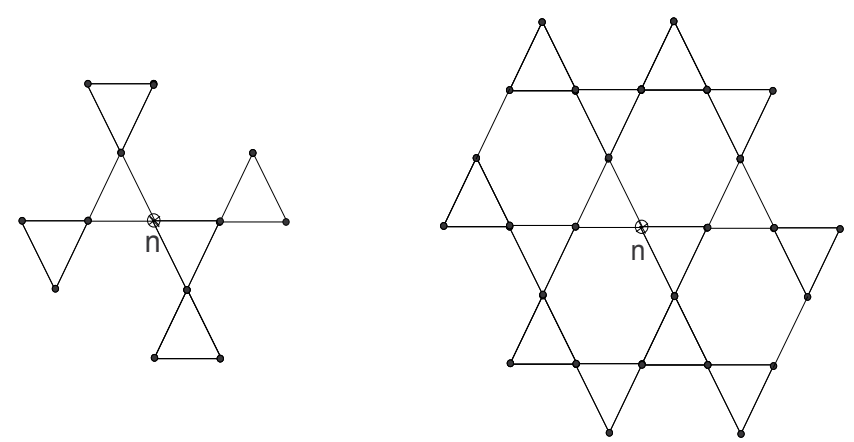

(a) and count the vertices on each horizontal line one by one then adding them for top to bottom we have.

For $\mathrm{D}=4 \mathrm{k}+1, \mathrm{k} \in \mathbb{N}$, then

$\left|\mathrm{V}\left(\mathrm{O}_{\mathrm{D}}\right)\right|=(2 \mathrm{k}+2)+(\mathrm{k}+1)+\ldots+(4 \mathrm{k}-2)+(2 \mathrm{k}-1)+4 \mathrm{k}+2 \mathrm{k}+(4 \mathrm{k}+$

$2)+(2 \mathrm{k}+1)+4 \mathrm{k}+2 \mathrm{k}+(4 \mathrm{k}-2)+\ldots+(\mathrm{k}+1)+(2 \mathrm{k}+2)$

$=9 \mathrm{k}^{2+9} \mathrm{k}+3$

For $\mathrm{D}=4 \mathrm{k}+3, \mathrm{k} \in \mathbb{N}$, then

$\left|\mathrm{V}\left(\mathrm{O}_{\mathrm{D}}\right)\right|=(\mathrm{k}+2)+(2 \mathrm{k}+4)+\ldots .+4 \mathrm{k}+(2 \mathrm{k}+1)+(4 \mathrm{k}+2)+(2 \mathrm{k}+2)+$

$(4 \mathrm{k}+4)+(2 \mathrm{k}+1)+(4 \mathrm{k}+2)+2 \mathrm{k}+4 \mathrm{k}+\ldots .+(\mathrm{k}+1)+(2 \mathrm{k}+2)$

$=9 \mathrm{k}^{2+} 18 \mathrm{k}+9$

In the Figures $3 a$ and $3 b$ the graphs $O_{D}$ for $D=5$ and $D=7$ are depicted. Where the vertices of central triangle of $\mathrm{O}_{\mathrm{D}}$ are denoted by a,b,c and is depicted by $\otimes$.

Hence we proved the following statement.

\section{Theorem 1.3}

Let $\mathrm{X}$ be the infinite oxide network. Then for the largest connected sub graph of $\mathrm{X}$ of maximum degree $\Delta=4$ and diameter $\mathrm{D}$ in terms of vertices we have the following two cases.

\section{Case (i)}

For $\mathrm{D}=4 \mathrm{k}, \mathrm{k} \in \mathbb{N}$, the largest connected subgraph of $\mathrm{X}$ with $\Delta=4$ denoted by $\mathrm{H}_{\mathrm{D}}$ is obtained by connecting the two oxygen vertices of the closed ball $\mathrm{O}_{\mathrm{D}}$ with only one vertex of $\mathrm{X}$. Such subgraph $\mathrm{H}_{\mathrm{D}}$ for $\mathrm{D}=4$ is shown in Figure 4.

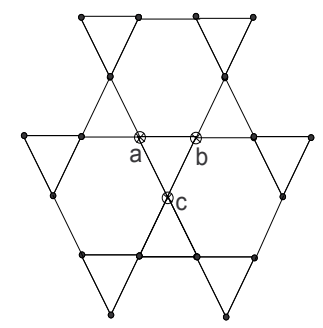

(a)

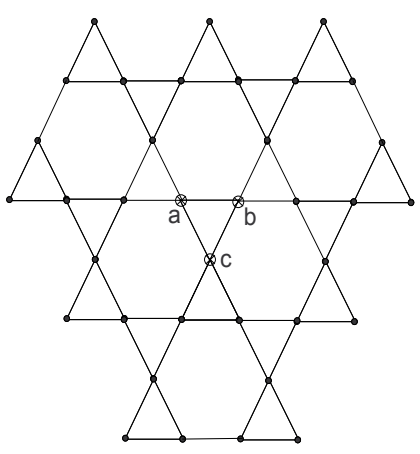

(b)
Figure 3: $O_{D}$ for $D=5$ and $D=7$.

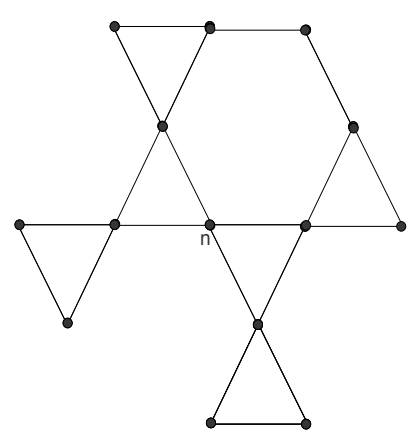

Figure 4: $H_{D}$ for $D=4$.

Figure 2: $O_{D}$ for $D=4$ and $D=6$. 
$\mathrm{N}_{\mathrm{X}}(4, \mathrm{D})=\left|\mathrm{V}\left(\mathrm{H}_{\mathrm{D}}\right)\right|=\left|\mathrm{V}\left(\mathrm{O}_{\mathrm{D}}\right)\right|+1$ for $\mathrm{D}=4 \mathrm{k}, \mathrm{k} \in \mathbb{N}$.

\section{Case (ii)}

For $\mathrm{D}=4 \mathrm{k}+\mathrm{r}, \mathrm{k} \in \mathbb{N}, \mathrm{r} \in\{1,2,3\}$, the largest subgraph of $\mathrm{X}$ with $\Delta=4$ is $\mathrm{O}_{\mathrm{D}}$ itself.

$\mathrm{N}_{\mathrm{X}}(4, \mathrm{D})=\left|\mathrm{V}\left(\mathrm{O}_{\mathrm{D}}\right)\right|$ for $\mathrm{D}=4 \mathrm{k}+\mathrm{r}, \mathrm{k} \in \mathbb{N}, \mathrm{r} \in\{1,2,3\}$.

The following statement is an immediate consequence of the previous theorem.

\section{Corollary 1.4}

Let $\mathrm{X}$ be the infinite oxide network. Let $\Delta, \mathrm{D}$ be positive integers, $\Delta$ $\leq 4$ and $\mathrm{D}=4 \mathrm{k}+\mathrm{r}, \mathrm{k} \in \mathbb{N}, \mathrm{r} \in\{0,1,2,3\}$. Then we have.

Case (i)

$\mathrm{N}_{\mathrm{X}}(\Delta, \mathrm{D}) \leq\left|\mathrm{V}\left(\mathrm{H}_{\mathrm{D}}\right)\right|$ for $\mathrm{D}=4 \mathrm{k}, \mathrm{k} \in \mathbb{N}$.

Case (ii)

$\mathrm{N}_{\mathrm{X}}(\Delta, \mathrm{D}) \leq\left|\mathrm{V}\left(\mathrm{O}_{\mathrm{D}}\right)\right|$ for $\mathrm{D}=4 \mathrm{k}+\mathrm{r}, \mathrm{k} \in \mathbb{N}, \mathrm{r} \in\{1,2,3\}$.

\section{Values for $\Delta \leq 3$}

\section{Values for $\Delta=1,2$}

Since for $\Delta \geq \Delta(\mathrm{X})$ we have

$\mathrm{N}_{\mathrm{x}}(\Delta, \mathrm{D})=\left|\mathrm{V}\left(\mathrm{H}_{\mathrm{D}}\right)\right|=\left|\mathrm{V}\left(\mathrm{O}_{\mathrm{D}}\right)\right|+1$ for $\mathrm{D}=4 \mathrm{k}, \mathrm{k} \in \mathbb{N}$. And

$\mathrm{N}_{\mathrm{X}}(\Delta, \mathrm{D})=\left|\mathrm{V}\left(\mathrm{O}_{\mathrm{D}}\right)\right|$ for $\mathrm{D}=4 \mathrm{k}+\mathrm{r}, \mathrm{k} \in \mathbb{N}, \mathrm{r} \in\{1,2,3\}$.

Now we consider the cases when maximum degree $\Delta \leq 3$.

Since for $\Delta=1$ and diameter $D=4 k+r, k \in \mathbb{N}, r \in\{0,1,2,3\}$, the largest sub graph of $\mathrm{X}$ is a complete graph $\mathrm{K}_{2}$.

Hence $\mathrm{N}_{\mathrm{X}}(1, \mathrm{D})=2$.

Now we discuss the case when $\Delta=2$.

\section{Theorem 2.1}

Let $\mathrm{X}$ be the infinite oxide network, then for $\mathrm{D} \geq 4$ we have $\mathrm{N}_{\mathrm{x}}(2, \mathrm{D})=2 \mathrm{D}+1$.

\section{Proof}

\section{Case (i)}

For $\mathrm{D}=4 \mathrm{k}, \mathrm{k} \in \mathbb{N}$, clearly the graph $\mathrm{H}_{\mathrm{D}}$ contains a cycle. Thus for $\mathrm{D}=4 \mathrm{k}, \mathrm{k} \in \mathbb{N}$, a largest subgraph of $\mathrm{X}$ having maximum degree 2 is a cycle of length $2 \mathrm{D}+1$.

In the Figure $5 \mathrm{a}$, for $\mathrm{D}=4$ and $\Delta=2$, such a cycle $n \rightarrow a \rightarrow b \rightarrow c \rightarrow d \rightarrow e \rightarrow f \rightarrow g \rightarrow h \rightarrow n$ of length $2 D+1$ in $H_{D}$ is shown. which implies that For $D=4 k, k \in \mathbb{N}$, such a sub graph of $H_{D}$ exist.

\section{Case (ii)}

For $D=4 k+r, k \in \mathbb{N}, r \in\{1,2,3\}$, Clearly the graph $O_{D}$ contains a cycle. Thus for $\mathrm{D}=4 \mathrm{k}+\mathrm{r}, \mathrm{k} \in \mathbb{N}, \mathrm{r} \in\{1,2,3\}$, a largest subgraph of $\mathrm{X}$ having maximum degree 2 is a cycle of length $2 \mathrm{D}+1$.

In the Figure 5b, such a cycle $x \rightarrow i \rightarrow j \rightarrow k \rightarrow l \rightarrow m \rightarrow 0 \rightarrow p \rightarrow q \rightarrow r \rightarrow s \rightarrow x$ for $\mathrm{D}=5$ in $\mathrm{O}_{\mathrm{D}}$ is shown. In the Figure $5 \mathrm{c}$, such a cycle $\mathrm{n} \rightarrow \mathrm{t} \rightarrow \mathrm{u} \rightarrow \mathrm{v} \rightarrow \mathrm{w} \rightarrow \mathrm{x} \rightarrow \mathrm{y} \rightarrow \mathrm{z} \rightarrow \mathrm{a} \rightarrow \mathrm{b} \rightarrow \mathrm{c} \rightarrow \mathrm{d} \rightarrow \mathrm{e} \rightarrow \mathrm{n}$ for $\mathrm{D}=6$ in $\mathrm{O}_{\mathrm{D}}$ is shown. In the Figure 5d, such a cycle $y \rightarrow f \rightarrow g \rightarrow h \rightarrow i \rightarrow j \rightarrow k \rightarrow l \rightarrow m \rightarrow n \rightarrow 0 \rightarrow p \rightarrow q \rightarrow r \rightarrow s \rightarrow y$ for $\mathrm{D}=7$ in $\mathrm{O}_{\mathrm{D}}$ is shown, which implies that For $\mathrm{D}=4 \mathrm{k}+\mathrm{r}, \mathrm{k} \in \mathbb{N}, \mathrm{r} \in\{1,2,3\}$, such a subgraph of $\mathrm{O}_{\mathrm{D}}$ exist.

Which completes the proof

\section{Bounds for $\Delta=3$}

Now we find the bounds for $\Delta=3$.

For even $\mathrm{D} \geq 4$, we have the following theorem.

\section{Theorem 2.2}

Let $\mathrm{X}$ be the infinite oxide network and $\mathrm{D} \geq 4$ be an even positive integer.

$$
\left|\mathrm{N}_{x}(3, \mathrm{D})\right| \geq\left\{\begin{array}{l}
10, \quad \text { for } D=4 . \\
38, \quad \text { for } D=8 . \\
\left|\mathrm{V}\left(\mathrm{H}_{\mathrm{D}}\right)\right|-(2 \mathrm{~K}+6), \quad \text { for } D=4 k+8, k \in \mathbb{N}
\end{array}\right.
$$

and

$$
\left|\mathrm{N}_{x}(3, \mathrm{D})\right| \geq\left\{\begin{array}{l}
21, \quad \text { for } D=6 . \\
\left|\mathrm{V}\left(\mathrm{O}_{\mathrm{D}}\right)\right|-(\mathrm{K}+5), \quad \text { for } D=4 k+8, k \in \mathbb{N}
\end{array}\right.
$$

\section{Proof}

Case (i)

Clearly the largest degree of the graphs $\mathrm{W}_{\mathrm{D}}$ (which are sub graphs of $\mathrm{H}_{\mathrm{D}}$, shown in Figures $6 \mathrm{a}$ and $6 \mathrm{~b}$ is at most 3. Where the isolated vertices shown in it do not belongs to the vertex set of $\mathrm{W}_{\mathrm{D}}$. One can also check that the diameter of the graphs $W_{D}$ is $D$. Hence the theorem holds for $\mathrm{D}=4,8$.

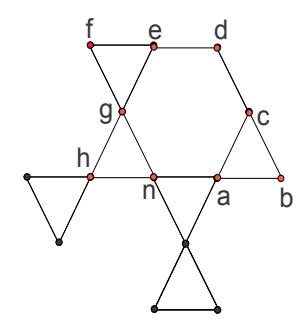

(a)

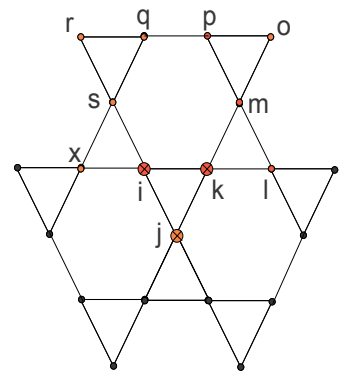

(b)

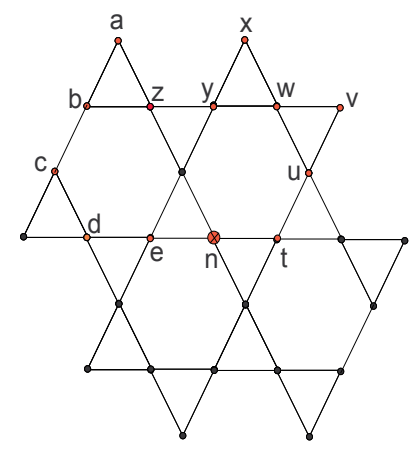

(c)

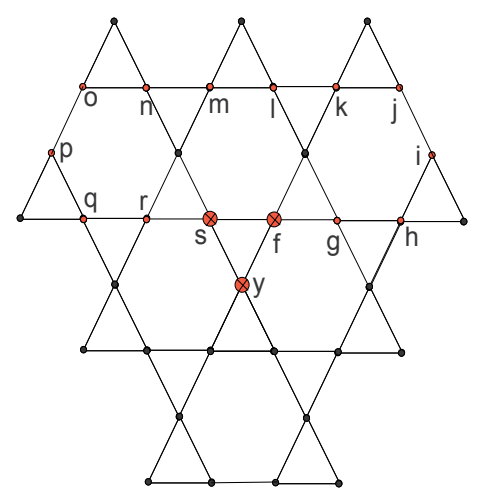

(d)

Figure 5: Graphs having cycles on 2D+1 vertices. 
Now we consider the graphs $\mathrm{W}_{\mathrm{D}}$ (which are sub graphs of $\mathrm{H}_{\mathrm{D}}$ for $\mathrm{D}=4 \mathrm{k}+8, \mathrm{k} \in \mathbb{N})$. Such graphs $\mathrm{W}_{\mathrm{D}}$ for $\mathrm{D}=12,16,20$ depicted in Figures $6 \mathrm{c}$, 7 and 8 , clearly having degree at most 3 . Where the isolated vertices shown in the graphs do not belongs to the vertex set of $\mathrm{W}_{\mathrm{D}}$. Also one can easily check the diameter of $\mathrm{W}_{\mathrm{D}}$ is $\mathrm{D}$.

Since $\left|\mathrm{V}\left(\mathrm{H}_{\mathrm{D}}\right)\right|=\left|\mathrm{V}\left(\mathrm{W}_{\mathrm{D}}\right)\right|+$ the number of isolated vertices, for $\mathrm{D}=4 \mathrm{k}+8, \mathrm{k} \in \mathbb{N}$.

The number of isolated vertices form a sequence $(2 \mathrm{k}+6)$ in the graphs $W_{D}$ for $D=4 k+8, k \in \mathbb{N}$. Hence the theorem holds for $D=4 k+8$, $\mathrm{k} \in \mathbb{N}$.

\section{Case (ii)}

Clearly the maximum degree of the graph $\mathrm{W}_{\mathrm{D}}$ (which is a sub graph of $\mathrm{O}_{\mathrm{D}}$, shown in Figure 9a is at most 3. Where the isolated vertices shown in it do not belong to the vertex set of $\mathrm{W}_{\mathrm{D}}$. One can also check that the diameter of the graphs $\mathrm{W}_{\mathrm{D}}$ is $\mathrm{D}$. Hence the theorem holds for $\mathrm{D}=6$.

Now we consider the graphs $\mathrm{W}_{\mathrm{D}}$ (which are sub graphs of $\mathrm{O}_{\mathrm{D}}$ for $\mathrm{D}=4 \mathrm{k}+6, \mathrm{k} \in \mathbb{N}$ ) clearly having degree at most 3 . Such graphs $\mathrm{W}_{\mathrm{D}}$ for $\mathrm{D}=10,14,18$ are depicted in Figures $9 \mathrm{~b}, 9 \mathrm{c}$ and 10 . Where the isolated vertices shown in the graphs do not belong to the vertex set of $\mathrm{W}_{\mathrm{D}}$. Note

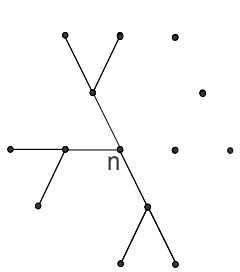

(a)

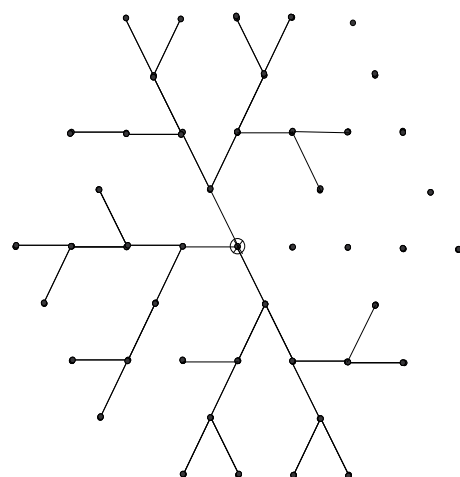

(b)

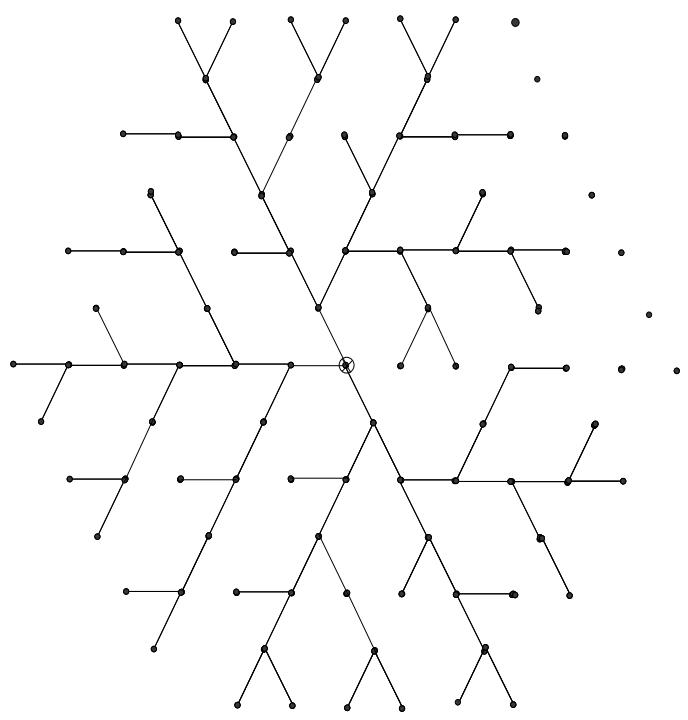

(c)

Figure 6: $W_{D}$ for $D=4,8,12$.
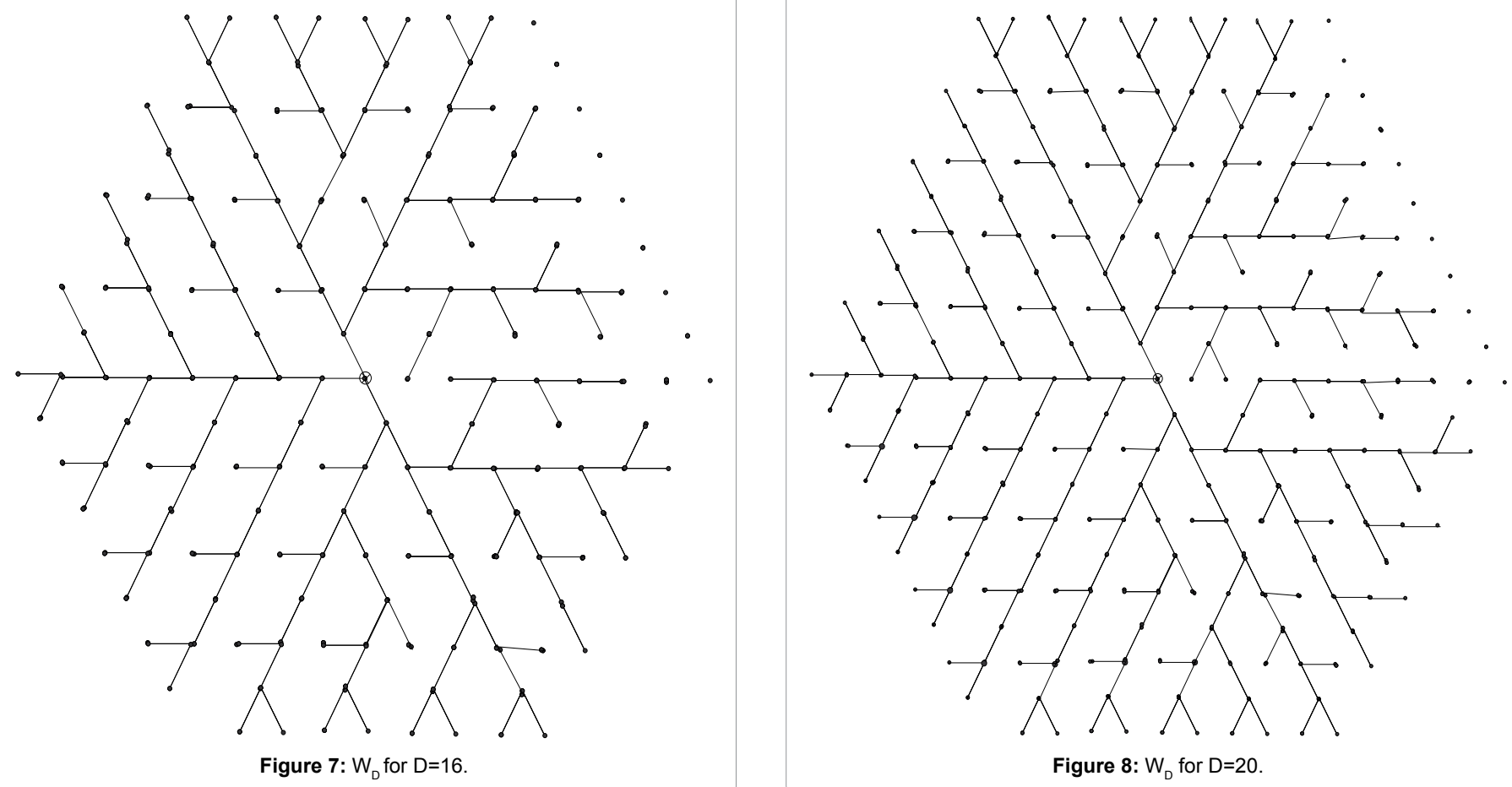


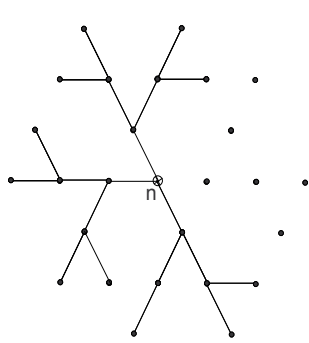

(a)

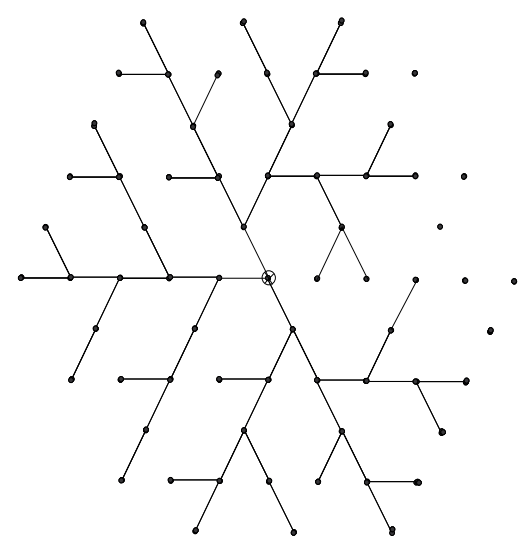

(b)

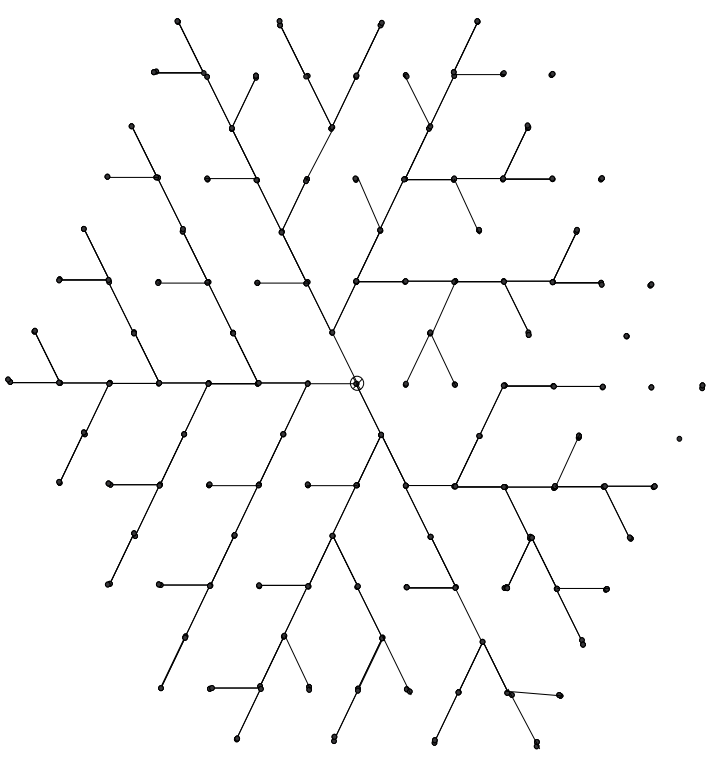

(c)

Figure 9: $W_{D}$ for $D=6,10,14$.

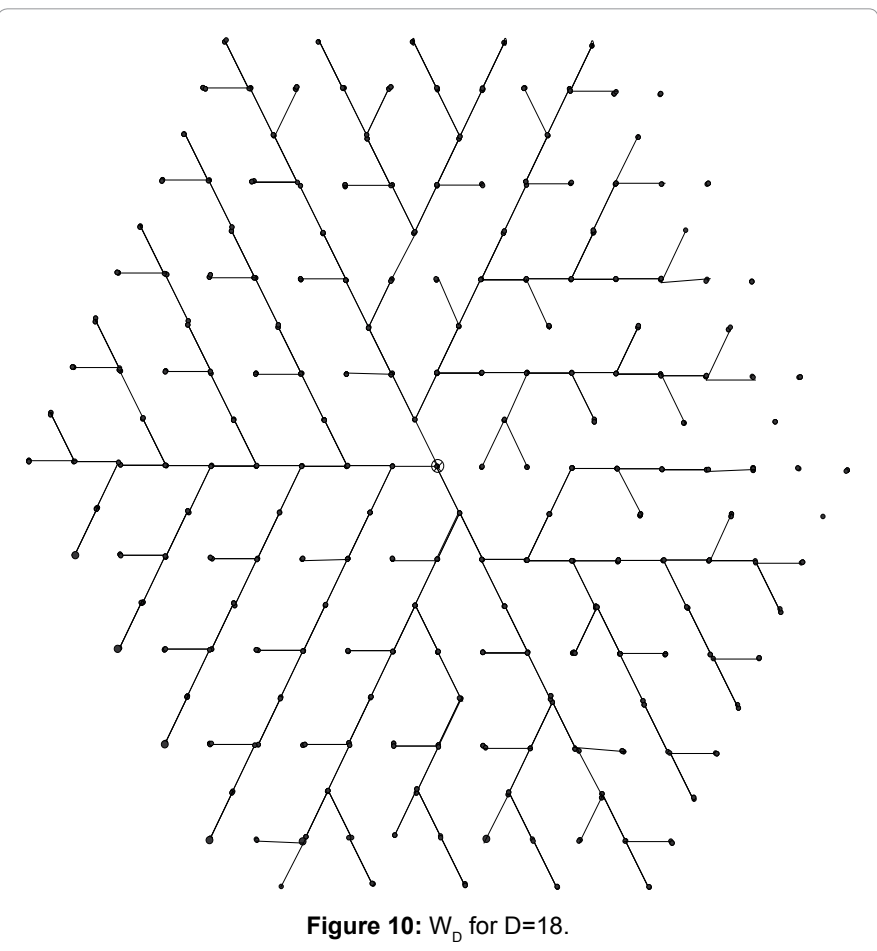

that the central vertex $n$ of $W_{D}$ corresponds to the central vertex of $O_{D}$ and is depicted by $\otimes$. Now we prove that the diameter of $\mathrm{W}_{\mathrm{D}}$ is $\mathrm{D}$. For this we have to prove that dist $_{w_{D}}(n, x) \leq \frac{D}{2}$ for every vertex $\mathrm{x}$ of $\mathrm{W}_{\mathrm{D}}$. Also one can easily check that all the vertices of $\mathrm{W}_{\mathrm{D}}$ are at distance at most $\frac{D}{2}$ from the central vertex $\mathrm{n}$. Hence the diameter of $\mathrm{W}_{\mathrm{D}}$ is at most $\mathrm{D}$. Since $\left|\mathrm{V}\left(\mathrm{O}_{\mathrm{D}}\right)\right|=\left|\mathrm{V}\left(\mathrm{W}_{\mathrm{D}}\right)\right|+$ the number of isolated vertices, for $\mathrm{D}=4 \mathrm{k}$ $+6, \mathrm{k} \in \mathbb{N}$.
The number of isolated vertices form a sequence $(k+5)$ in the graphs $W_{D}$ for $D=4 k+6, k \in \mathbb{N}$. Hence the theorem holds for $D=4 k+6, k \in \mathbb{N}$.

Which completes the proof.

For odd $\mathrm{D}>4$, we prove the following theorem.

\section{Theorem 2.3}

Let $\mathrm{X}$ be the infinite oxide network and $\mathrm{D}>4$ be an odd positive integer. Then

$\left|\mathrm{N}_{x}(3, \mathrm{D})\right| \geq\left\{\left|\mathrm{V}\left(\mathrm{O}_{\mathrm{D}}\right)\right|-9, \quad\right.$ for $D=4 k+8, k \in \mathbb{N}$ for $\mathrm{D}=4 \mathrm{k}+1, \mathrm{k} \in \mathbb{N}$.

and

$$
\left|\mathrm{N}_{x}(3, \mathrm{D})\right| \geq\left\{\begin{array}{l}
24, \quad \text { for } D=6 . \\
\left|\mathrm{V}\left(\mathrm{O}_{\mathrm{D}}\right)\right|-9, \quad \text { for } D=4 k+8, k \in \mathbb{N}
\end{array}\right.
$$

\section{Proof:}

Case (i)

Now we consider the graphs $\mathrm{W}_{\mathrm{D}}$ (which are sub graphs of $\mathrm{O}_{\mathrm{D}}$ for $\mathrm{D}=4 \mathrm{k}+1, \mathrm{k} \in \mathbb{N}$ ). Such graphs $\mathrm{W}_{\mathrm{D}}$ for $\mathrm{D}=5,9,13,17$ are depicted in Figures $11 \mathrm{a}, 11 \mathrm{~b}, 11 \mathrm{c}$ and 12 , clearly having degree at most 3 . Where the isolated vertices shown in the graphs do not belongs to the vertex set of $\mathrm{W}_{\mathrm{D}}$. Note that the central triangle of $\mathrm{W}_{\mathrm{D}}$ corresponds to the central triangle of $\mathrm{O}_{\mathrm{D}}$ and its vertices are shown by $\otimes$. Now we prove that the diameter of $\mathrm{W}_{\mathrm{D}}$ is $\mathrm{D}$. One can also check that all the vertices are at distance at most $\frac{D-1}{2}$ from the closest vertex of central triangle in $\mathrm{W}_{\mathrm{D}}$. Hence the diameter of $\mathrm{W}_{\mathrm{D}}$ is at most $\mathrm{D}$.

Since $\left|\mathrm{V}\left(\mathrm{O}_{\mathrm{D}}\right)\right|=\left|\mathrm{V}\left(\mathrm{W}_{\mathrm{D}}\right)\right|+$ the number of isolated vertices, for $\mathrm{D}=4 \mathrm{k}+1, \mathrm{k} \in \mathbb{N}$.

The number of isolated vertices is 9 in the graphs $\mathrm{W}_{\mathrm{D}}$ for $\mathrm{D}=4 \mathrm{k}+1, \mathrm{k} \in \mathbb{N}$. Hence the theorem holds for $\mathrm{D}=4 \mathrm{k}+1, \mathrm{k} \in \mathbb{N}$.

Case (ii)

Clearly the maximum degree of the graph $\mathrm{W}_{\mathrm{D}}$ (which is a sub graph 


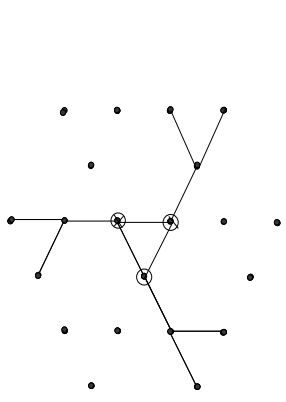

(a)

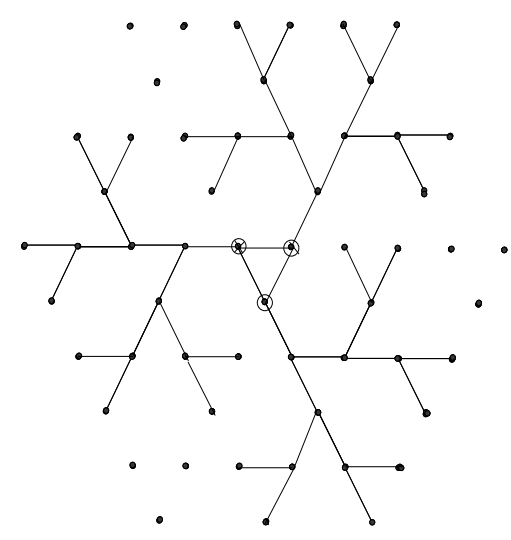

(b)

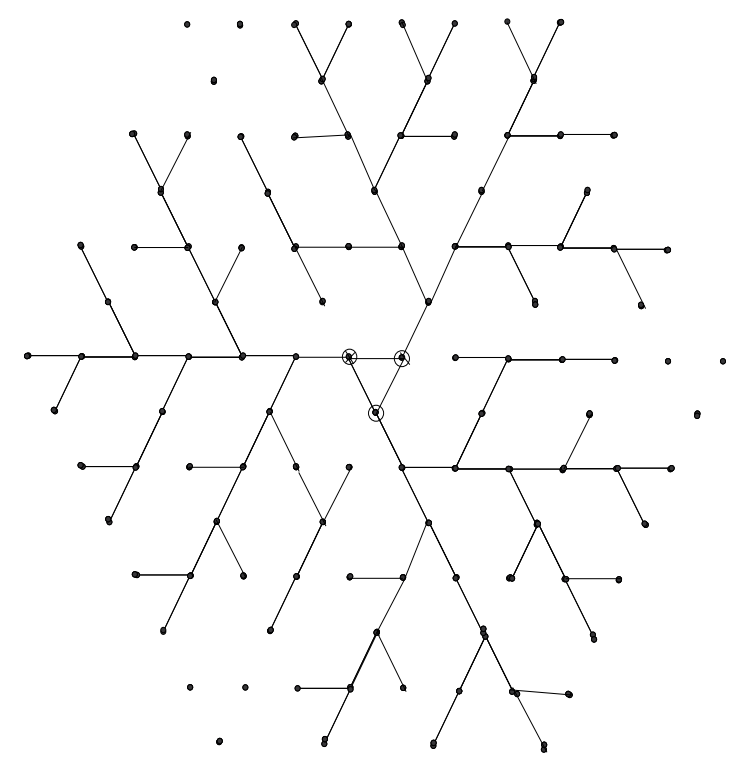

(c)

Figure 11: $W_{D}$ for $D=5,9,13$.

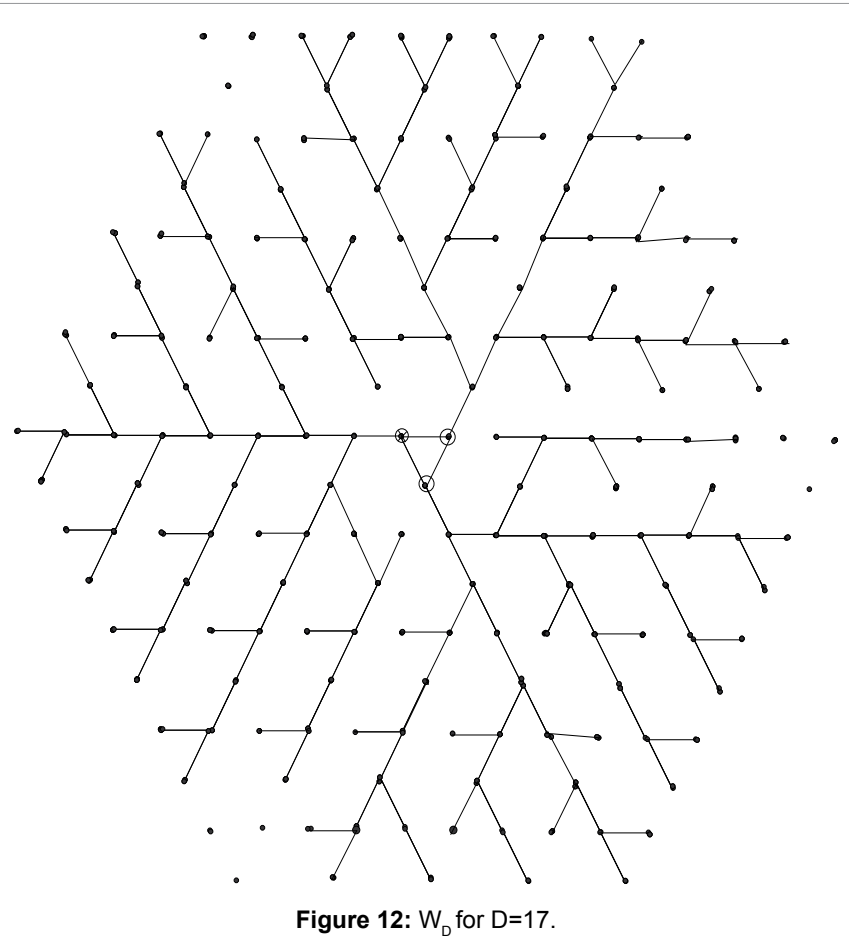

of $\mathrm{O}_{\mathrm{D}}$, shown in Figure 13a is at most 3. Where the isolated vertices shown in it do not belongs to the vertex set of $\mathrm{W}_{\mathrm{D}}$. One can also check that the diameter of the graph $\mathrm{W}_{\mathrm{D}}$ is $\mathrm{D}$ because all the vertices are at distance at most $\frac{D-1}{2}$ from the closest vertex of central triangle in $\mathrm{W}_{\mathrm{D}}$. The vertices of the central triangle of $\mathrm{W}_{\mathrm{D}}$ are emphasized by $\otimes$. Hence the theorem holds for $\mathrm{D}=7$.

Now we consider the graphs $\mathrm{W}_{\mathrm{D}}$ (which are sub graphs of $\mathrm{O}_{\mathrm{D}}$ for
$\mathrm{D}=4 \mathrm{k}+7, \mathrm{k} \in \mathbb{N})$. Such graphs $\mathrm{W}_{\mathrm{D}}$ for $\mathrm{D}=11,15,19$ depicted in Figures $13 \mathrm{~b}, 13 \mathrm{c}$ and 14 , clearly having degree at most 3 . Where the isolated vertices shown in the graphs do not belongs to the vertex set of $\mathrm{W}_{\mathrm{D}}$. Note that the central triangle of $\mathrm{W}_{\mathrm{D}}$ corresponds to the central triangle of $\mathrm{O}_{\mathrm{D}}$ and its vertices are shown by $\otimes$. Hence it remains to show that the diameter of $\mathrm{W}_{\mathrm{D}}$ is $\mathrm{D}$. As can be seen, all the vertices are at distance at most $\frac{D-1}{2}$ from the closest vertex of central triangle in $\mathrm{W}_{\mathrm{D}}$. Hence the diameter of $\mathrm{W}_{\mathrm{D}}$ is at most $\mathrm{D}$. 


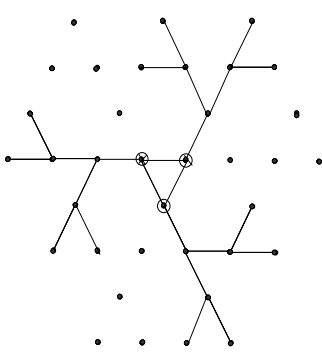

(a)

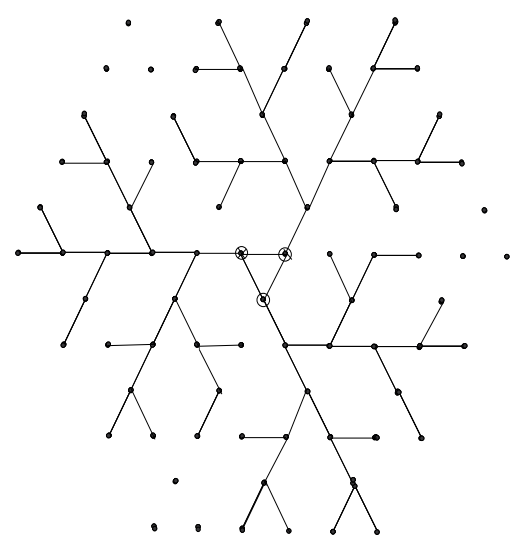

(b)

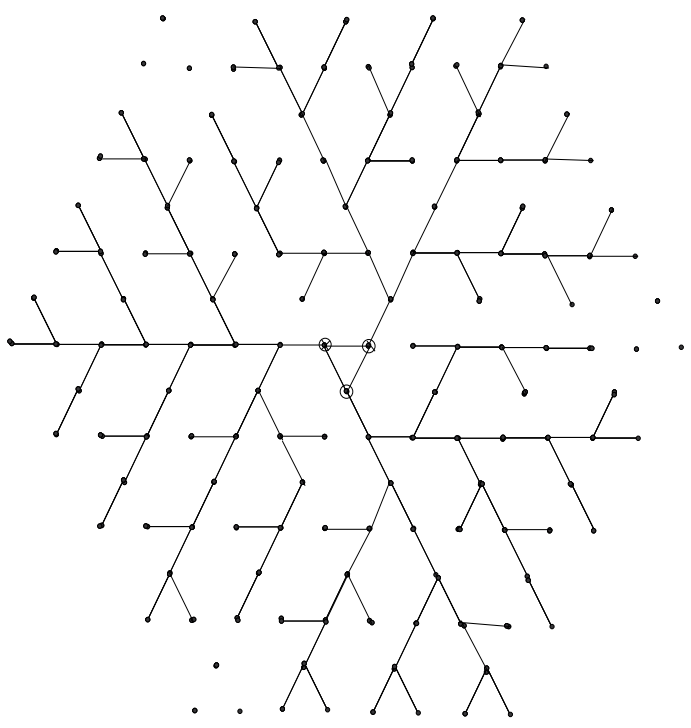

(c)

Figure 13: $W_{D}$ for $D=7,11,15$

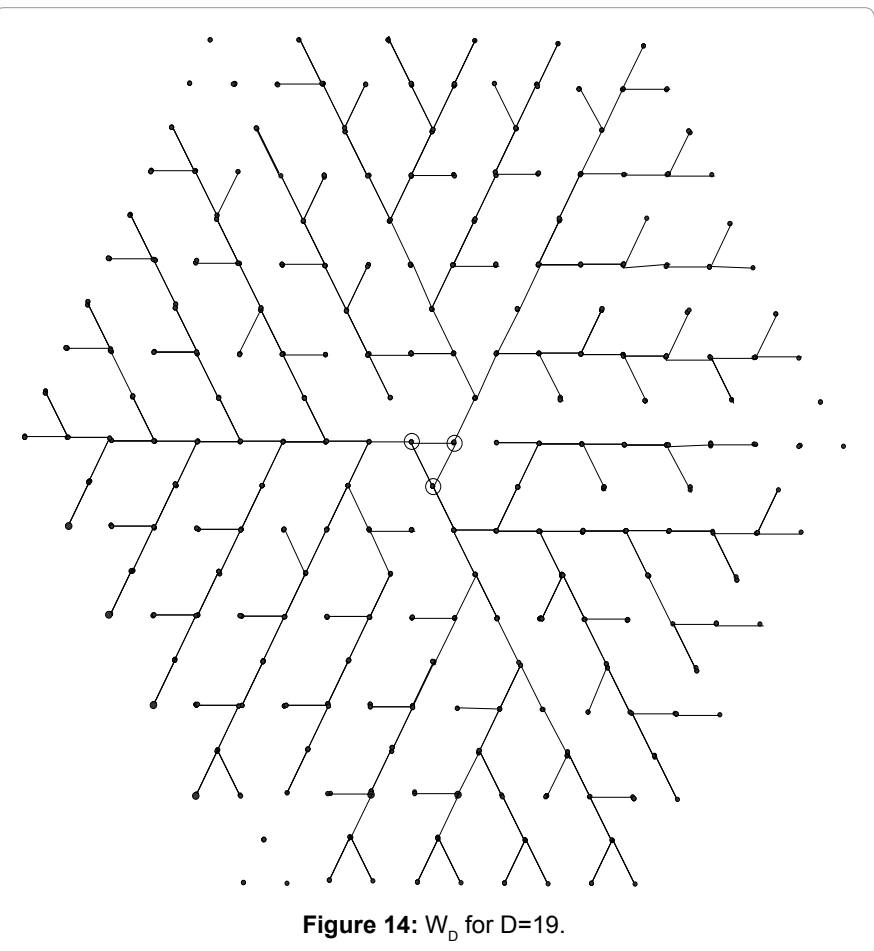

Since $\left|\mathrm{V}\left(\mathrm{O}_{\mathrm{D}}\right)\right|=\left|\mathrm{V}\left(\mathrm{W}_{\mathrm{D}}\right)\right|+$ the number of isolated vertices, for $\mathrm{D}=4 \mathrm{k}+7, \mathrm{k} \in \mathbb{N}$.

The number of isolated vertices is 9 in the graphs $W_{D}$ for $\mathrm{D}=4 \mathrm{k}+7, \mathrm{k} \in \mathbb{N}$. Hence the theorem holds for $\mathrm{D}=4 \mathrm{k}+7, \mathrm{k} \in \mathbb{N}$.

Which completes the proof.

Using the fact that $\mathrm{N}_{\mathrm{G}}(\Delta-1, \mathrm{D}) \leq \mathrm{N}_{\mathrm{G}}(\Delta, \mathrm{D})$ for any graph $\mathrm{G}$, we get the following statement [6].

\section{Corollary 2.4}

Let $\mathrm{X}$ be the infinite oxide network. Then

$\left|\mathrm{V}\left(\mathrm{H}_{\mathrm{D}}\right)\right|-(2 \mathrm{k}+6) \leq \mathrm{N}_{\mathrm{x}}(3, \mathrm{D}) \leq\left|\mathrm{V}\left(\mathrm{H}_{\mathrm{D}}\right)\right|$ for $\mathrm{D}=4 \mathrm{k}+8, \mathrm{k} \in \mathbb{N}$.

$\left|\mathrm{V}\left(\mathrm{O}_{\mathrm{D}}\right)\right|-(\mathrm{k}+5) \leq \mathrm{N}_{\mathrm{x}}(3, \mathrm{D}) \leq\left|\mathrm{V}\left(\mathrm{O}_{\mathrm{D}}\right)\right|$ for $\mathrm{D}=4 \mathrm{k}+6, \mathrm{k} \in \mathbb{N}$.

$\left|\mathrm{V}\left(\mathrm{O}_{\mathrm{D}}\right)\right|-9 \leq \mathrm{N}_{\mathrm{X}}(3, \mathrm{D}) \leq\left|\mathrm{V}\left(\mathrm{O}_{\mathrm{D}}\right)\right|$ for $\mathrm{D}=4 \mathrm{k}+1, \mathrm{k} \in \mathbb{N}$.

$\left|\mathrm{V}\left(\mathrm{O}_{\mathrm{D}}\right)\right|-9 \leq \mathrm{N}_{\mathrm{X}}(3, \mathrm{D}) \leq\left|\mathrm{V}\left(\mathrm{O}_{\mathrm{D}}\right)\right|$ for $\mathrm{D}=4 \mathrm{k}+7, \mathrm{k} \in \mathbb{N}$.

\section{References}

1. Bondy A, Murty MR (2008) Graph Theory. Springer.

2. Manuel P, Rajasingh I (2011) Minimum Metric Dimension of Silicate Networks.

3. Manuel P, Rajasingh I (2009) Topological properties of Silicate Networks. IEEE Xplore.

4. Simonraj F, George A (2013) Topological properties of few Poly Oxide, Poly Silicate, DOX and DSL Networks. International Journal of Future Computer and communication 2.

5. Holub P, Miller M, Perez-Roses H, Ryan J (2014) Degree Diameter Problem on Honeycomb Networks. Discrete Applied Mathematics 179: 139-151.

6. Holub P, Ryan J (2015) Degree Diameter Problem on Triangular Networks Australasian Journal of Combinatorics 63: 333-345.

7. Miller M, Perez-Roses H, Ryan J (2012) The Maximum Degree and Diameter Bounded Sub graph in the Mesh, Discrete Applied Mathematics 160: 1782-1790.

8. Xu K, Takahara G, Hassanein H (2006) On the Robustness of Grid-based Deployment in Wireless Sensor Networks. Proceedings of the 2006 international conference on Wireless communications and mobile computing pp:1183-1188.

9. Zhang $Y$, Zhou Y, Fang Y (2005) Key Establishment in sensor networks based on triangular grid deployment model. Military Communications Conference Atlantic City.

10. Perez-Roses H, Dekker A, Pineda VG, Watters $P$ (2002) The maximum degree and diameter-bounded sub graph and its applications. Journal of Mathematical Modeling and Algorithms 11: 249-268.

11. Miller M, Sira J (2013) Moore graphs and beyond: a survey of the degree/ diameter problem. The Electronic Journal of Combinatorics pp: 1-92.

12. Perez-Roses LEH, Pineda VG (2012) Combinatoricswiki.org, updated March 2012. 